University of Wollongong

Research Online

Faculty of Engineering and Information

Faculty of Engineering and Information

Sciences - Papers: Part B

Sciences

2018

Formulation of a model predictive control algorithm to enhance the performance of a latent heat solar thermal system

\author{
Gianluca Serale \\ Politecnico di Torino, gianluca.serale@polito.it \\ Massimo Fiorentini \\ University of Wollongong, massimo@uow.edu.au \\ Alfonso Capozzoli \\ Politecnico di Torino, alfonso.capozzoli@polito.it \\ Paul Cooper \\ University of Wollongong, pcooper@uow.edu.au \\ Marco Perino \\ Politecnico di Torino
}

Follow this and additional works at: https://ro.uow.edu.au/eispapers1

Part of the Engineering Commons, and the Science and Technology Studies Commons

Research Online is the open access institutional repository for the University of Wollongong. For further information contact the UOW Library: research-pubs@uow.edu.au 


\title{
Formulation of a model predictive control algorithm to enhance the performance of a latent heat solar thermal system
}

\begin{abstract}
Model predictive control has proved to be a promising control strategy for improving the operational performance of multi-source thermal energy generation systems with the aim of maximising the exploitation of on-site renewable resources. This paper presents the formulation and implementation of a model predictive control strategy for the management of a latent heat thermal energy storage unit coupled with a solar thermal collector and a backup electric heater. The system uses an innovative Phase Change Material slurry for both the heat transfer fluid and storage media. The formulation of a model predictive controller of such a closed-loop solar system is particularly desirable but also challenging mainly due to the nonlinearity of the heat exchange and thermal storage processes involved. A solution for the model predictive control problem to regulate a system with intrinsic nonlinearities is introduced using a mixed logic-dynamical approach. The model predictive control regulation is tested and compared with a baseline rule-based controller considering both ideal and estimated disturbance predictions. Results demonstrate the capability of the predictive controller in anticipating future disturbances and in optimising the utilisation of the more efficient energy sources. When compared to the rule-based controller, the model predictive control algorithm leads to reductions of the system primary energy demand ranging from $19.2 \%$ to $31.8 \%$ as a function of the variation of a soft constraint on meeting demand constraints. The work contributes to new knowledge on how model predictive control algorithms can be implemented to maximise the benefits of integrating thermal energy storages that employ latent heat of fusion with solar thermal technologies.
\end{abstract}

\section{Keywords}

heat, latent, thermal, formulation, model, predictive, system, control, solar, algorithm, enhance, performance

Disciplines

Engineering | Science and Technology Studies

\section{Publication Details}

Serale, G., Fiorentini, M., Capozzoli, A., Cooper, P. \& Perino, M. (2018). Formulation of a model predictive control algorithm to enhance the performance of a latent heat solar thermal system. Energy Conversion and Management, 173 438-449. 


\title{
Formulation of a model predictive control algorithm to enhance the performance of a latent heat solar thermal system
}

\author{
Gianluca Serale, Alfonso Capozzoli ${ }^{*}$, Marco Perino \\ Department of Energy, DENERG, TEBE Research Group \\ Politecnico di Torino, Turin, Italy \\ e-mail: gianluca.serale@polito.it, alfonso.capozzoli@polito.it, marco.perino@polito.it \\ Massimo Fiorentini, Paul Cooper \\ Sustainable Buildings Research Centre, Faculty of Engineering and Information Sciences, \\ University of Wollongong, Wollongong, Australia (NSW) \\ e-mail: massimo@,uow.edu.au, pcooper@uow.edu.au
}

\begin{abstract}
Model predictive control opens up possibilities of improving the operational performance of multi-source thermal energy generation systems when coupled with thermal energy store, by maximising the exploitation of on-site renewable resources. In this paper, the formulation of a model predictive control problem for the control of a thermal energy store coupled with a solar thermal collector and a backup electric heater is introduced. The system uses a phase change slurry as heat transfer fluid, allowing the possibility of utilising the latent heat of the fluid itself. The numerical models developed in this study were calibrated with datasets from an experimental rig. Simulations of the model predictive control behaviour in a closed loop were performed with the aim of assessing the performance associated with the application of an optimal control strategy that is able to anticipate future disturbances, and therefore increase and optimise the exploitation of the renewable energy sources.
\end{abstract}

\section{KEYWORDS}

Model Predictive Control, Thermal Energy Store, solar system, Phase Change Material, Phase Change Slurry, Renewable Energy Source

\section{INTRODUCTION}

The pursuance of higher levels of thermal comfort has led to a dramatic increase in the use of energy in our buildings in recent times. At the time of writing the overall energy demand of the building sector in Europe accounts for about $40 \%$ of total energy consumption [1]. Thus, there is a pressing need to look for suitable technologies and strategies that facilitate the improvement of energy efficiency of buildings. To achieve this goal building energy consumption can be minimised through efficient envelope and HVAC system technologies. In addition, the remaining building energy demand could be covered by means of integrated renewable energy sources. Solar technologies are the leading renewable energy solution suitable for meeting this challenge. However, the benefit of solar energy is often limited to a great extent by its stochastic variation during time and the mismatch between its availability and the energy demand of buildings and consumers. Thus, energy storage strategies are required to partially mitigate this gap between availability and exploitation of solar technologies. A particularly promising technology is represented by compact thermal energy

${ }^{*}$ Corresponding author 
stores, which allows energy production to be decoupled from solar energy availability. In particular, the exploitation of latent heat thermal energy stores represents an effective way of reducing the thermal energy store size and to improve the overall performance by reducing system temperatures and the global energy losses [2].

In the last few years, the application of latent heat thermal energy stores in building applications has been extensively researched. In particular, one of the most effective solutions for latent heat thermal energy store is considered to be the adoption of embedded Phase Change Materials (PCMs) [3]. PCMs are substances (organic, inorganic, and eutectic) characterised by a high heat of fusion and temperatures of phase transition suitable for specific building applications. Up to now PCMs have been successfully implemented in thermal energy stores adopting different configurations according to the primary goal of the technology (e.g. cold storage, heat storage, matching with renewable energy sources). Specifically, the coupling of PCMs with solar thermal systems integrated in buildings has been investigated in several applications, with promising results. Active PCM-based thermal energy store can be directly integrated in the solar collector $[4,5]$ or placed in a storage tank where the collector Heat Transfer Fluid (HTF) flows [6, 7].

These innovative PCM-based solar thermal systems and thermal energy store need to be controlled in an optimal way to be effective and to exploit all their potentialities. Indeed, the classical control methods could not always be able to obtain the maximum benefits achievable by these technologies. The investigation of new control paradigms is therefore necessary. For this purpose, Model Predictive Control (MPC) is a well-established method in the industry for optimised constrained control, and recently it has also received attention in the field of building control. It is based on principles of classical control and optimisation. MPC is also becoming increasingly viable because of the increase in computational power of building automation systems and the availability of a large amount of monitored building data.

MPC has been successfully implemented in the thermal regulation of buildings, e.g. to fully exploit the potential of building thermal mass in Thermally Activated Building Structures (TABS) $[8,9]$. Moreover, MPC has been effectively applied to active energy stores, as well as the optimal management of on-site renewable energy sources [10,11]. MPC uses the prediction of future disturbances (e.g. internal gains, weather, etc.) and constraints on the controlled variables to find the control sequence that optimises an objective function. In general, an optimisation based control strategy allows the trade-off between contrasting functions (e.g. reducing the operative building energy costs while ensuring a satisfactory thermal comfort for building users) to be properly found.

Using an MPC algorithm for smart control of a solar thermal system and thermal energy store is not a trivial problem $[12,13,14]$. The heat exchanges processes involved in the system are intrinsically non-linear, thus the optimization problem presents a particular challenge. Moreover, the adoption of PCM in the controlled process introduces further non-linearity due to latent heat transfer at the temperatures of operation.

The present paper describes how these challenges may be surmounted for a solar thermal collector and a thermal energy store based on a particular PCM system, i.e. a Phase Change Slurry (PCS), which is used both as a HTF and a storage medium. In the first part of the paper, the case study was introduced and the MPC problem was formulated. Afterwards, the results of different simulations, calibrated with real data gathered on-field, were presented. In 
the conclusion, the main outcomes of the research are outlined and the future opportunities related to the implementation of the MPC algorithm are briefly discussed.

\section{PHASE CHANGE SLURRY SOLAR THERMAL SYSTEM}

The present paper focuses on the control of a prototype system consisting of a solar thermal collector coupled with an active thermal energy store, using a PCS capable of exploiting latent heat as heat transfer and energy storage fluid in a closed loop. In particular, the prototype was designed for operating during winter conditions to deliver heating energy at relatively low temperatures (e.g. radiant panels or Thermal Activated Building Elements). The thermal energy store is coupled to a primary renewable heat source, a $2.1 \mathrm{~m}^{2}$ flat plate solar thermal collector, and to a $1.5 \mathrm{~kW}$ auxiliary electrical heater that can be operated when renewable energy source generation is insufficient to meet the space heating demand. The MPC formulation presented in this study can be adapted to different renewable energy sources and auxiliary heat sources (e.g. a natural gas boiler, electric heat pump). Heat is delivered to the building through a secondary heat exchanger placed inside the thermal energy store. The solar thermal system prototype is shown in Figure 1 and a detailed description of the system can be found in [15]. The use of PCS as a heat transfer fluid allows the system performance to be increased by reducing HTF and thermal energy store temperatures. The temperature reduction helps with reducing the heat losses in the whole system and with increasing the solar fraction of the solar collector [16].

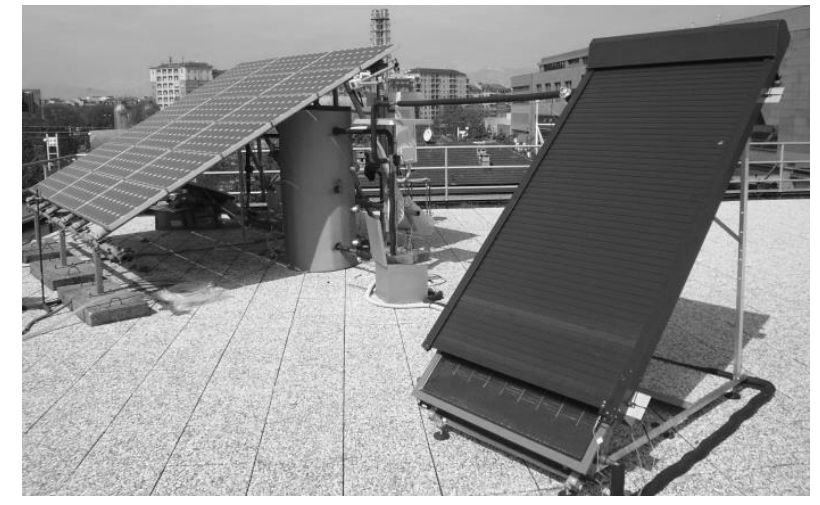

Figure 1. The PCS-based solar thermal system prototype.

A numerical model was developed to evaluate the system efficiency under dynamic environmental conditions. The model used in this study was developed in Matlab-Simulink and it is based on the work presented in [17].

In the present paper a lumped thermal model of the thermal energy store was also developed in order to simulate the whole solar thermal system and evaluate its performance in the closed loop. The output of the collector was calculated using a numerical model of the panel, discretising the heat transfer in ten segments of equal length. These segments were considered as lumped thermal nodes where the energy balance was calculated and where the PCS has constant thermodynamic features (e.g. temperature, specific enthalpy, conductivity, etc.). Furthermore, the model makes use of experimental specific enthalpy vs. temperature curves of PCS, defined through look-up tables to calculate the property of the material.

The real prototype was monitored for 15 days in order to gather the data necessary to calibrate the model parameters. After the calibration process the numerical model and experimental results showed a relatively small mismatch, with a Mean Absolute Percentage Error (MAPE) 
of $8 \%$ for the useful heat produced by the collector, and a Mean Absolute Error (MAE) of $0.5^{\circ} \mathrm{C}$ for the thermal energy store temperature.

The standard regulation in the prototype system is achieved using a Proportional Integrative (PI) controller outlined in Figure 2 (a). The controller's goal is to maintain the PCS temperature at outlet of the collector as close as possible to a reference set-point temperature. The set-point chosen at design stage was $40{ }^{\circ} \mathrm{C}$, which is slightly above the upper limit of the material phase change transition temperature.

The numerical model with the implementation of MPC is presented in Figure 2 (b). The MPC algorithm aims at optimising the operation of the collector by controlling the PCS flow-rate and the utilisation of the auxiliary heater, by dynamically finding the optimal set of control inputs without the need of predefined set-points or schedules. The MPC controller discretises the pump control signal in four fixed operating flow-rates $(0$ 1/h, 10 1/h, 60 1/h and 90 1/h) in order to maximise the exploitation of the solar source.
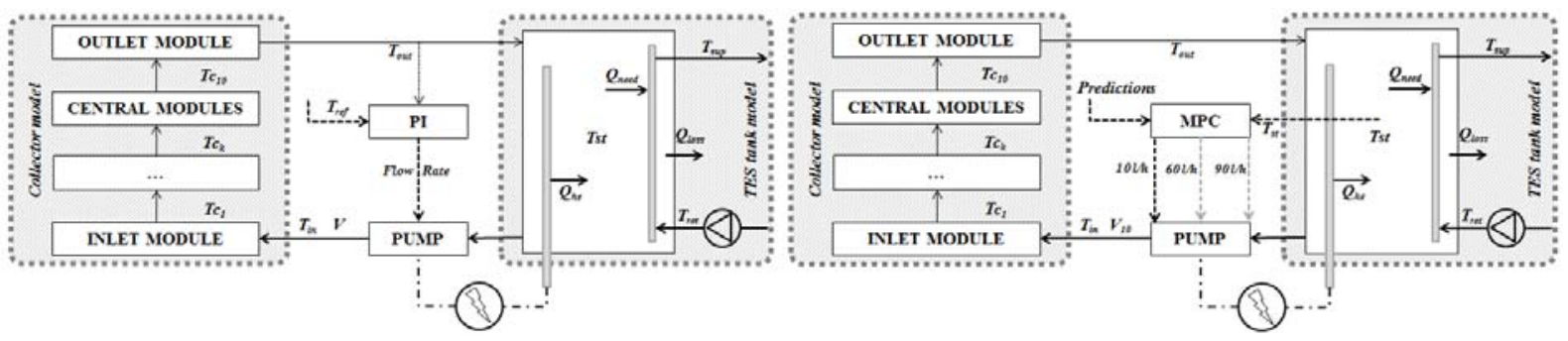

Figure 2. a) Schematic of the solar thermal system with the PI control loop implemented. b) Schematic of the solar thermal system with the MPC controller implemented.

The PCS used in this solar thermal system consisted of a mixture of water, glycol and a dispersed micro-encapsulated Phase Change Material (PCM). Micro-capsules allow the PCS to be pumpable regardless of the state of aggregation of the PCM material contained in the core. The PCM selected for this application was n-eicosane with a nominal melting temperature around $36{ }^{\circ} \mathrm{C}$ and a specific enthalpy of fusion equal to $195 \mathrm{~kJ} / \mathrm{kg}$. However, a particular feature of PCS is that its thermo-physical properties are not only dependent on the typology of PCM included in the micro-capsules but also of the weight concentration of the micro-capsules in the mixture. The system studied in this paper used a concentration of $30 \%$ w.t. of micro-capsules in PCS mixture.

Knowledge of the specific enthalpy vs. temperature curve of the PCS at $30 \%$ w.t concentration was necessary to determine the thermos-dynamical behaviour of the material. A T-History experimental procedure was carried out for this purpose [18]. In order to ensure the linearity of the model, as required by the MPC optimisation, experimental data were approximated by three-segment piecewise-linear correlations. The results providing the best match between the experimental data and the piecewise approximation are illustrated in Figure 3 and Table 1. It is possible to notice that when the PCS is in the solid phase, its specific heat is slightly higher than the one of water. This is due to a small amount of phase change transition, caused by rotator-crystal transition [19] occurring in the interval below 30 ${ }^{\circ} \mathrm{C}$. To compute the optimal solution, the energy cost of each pump speed was also necessary. The electrical energy consumption of the pump at the fixed PCS flow-rates is reported in Table 2. 
Table 1. The PCS thermo-dynamical characteristics.

\begin{tabular}{|c|c|c|c|}
\hline$T_{\text {inf }, P C S}$ & 33.9 & ${ }^{\circ} \mathrm{C}$ & Lower phase change temperature of the PCS \\
\hline$T_{\text {sup }, P C S}$ & 36.1 & ${ }^{\circ} \mathrm{C}$ & Higher phase change temperature of the PCS \\
\hline$c_{p, P C S, l i}$ & 5.47 & $\mathrm{~kJ} / \mathrm{kgK}$ & Specific heat of the PCS in solid phase \\
\hline$c_{p, P C S, t r}$ & 26.10 & $\mathrm{~kJ} / \mathrm{kgK}$ & $\begin{array}{l}\text { Dummy specific heat of the PCS during } \\
\text { transition }\end{array}$ \\
\hline$d h_{P C S, t r}$ & 57.42 & $\mathrm{~kJ} / \mathrm{kg}$ & Total phase change specific enthalpy of the PCS \\
\hline$c_{p, P(}$ & 3.52 & $\mathrm{~kJ} / \mathrm{kgK}$ & Specific heat of the PCS in liquid phase \\
\hline
\end{tabular}

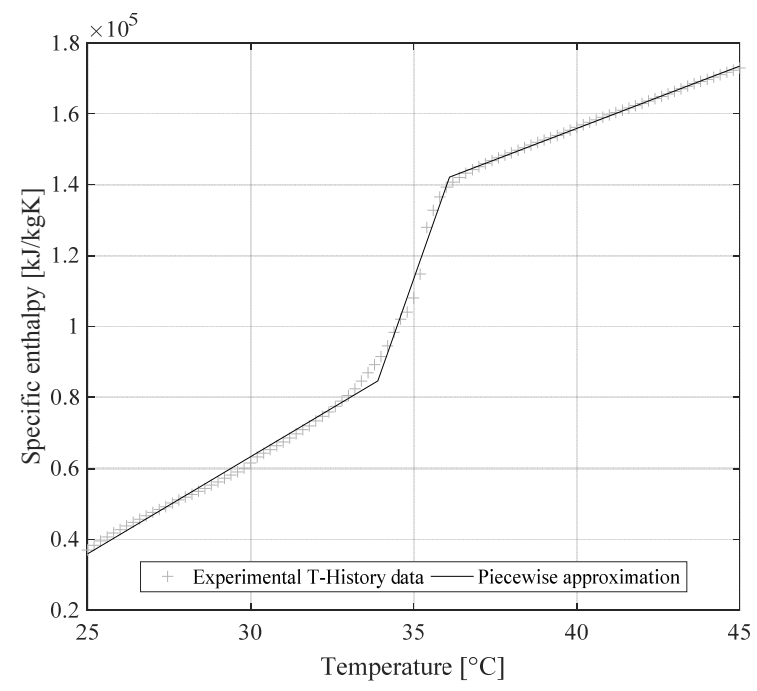

Figure 3. Three-segment piecewise approximation of specific enthalpy vs. temperature curve carried out by means of the T-History method.

Table 2. Pump flow-rates and related electric power consumptions.

\begin{tabular}{ccc}
\hline \multicolumn{2}{c}{ Flow-rate } & Power \\
$l / h$ & $m^{3} / s$ & $W$ \\
\hline 10 & $2.78 \mathrm{e}-6$ & 5 \\
60 & $1.67 \mathrm{e}-5$ & 25 \\
90 & $2.50 \mathrm{e}-5$ & 55 \\
\hline
\end{tabular}

\section{FORMULATION OF THE MODEL PREDICTIVE CONTROL SYSTEM}

The MPC formulation requires the introduction of a simplified control-oriented model, which describes the dynamic evolution of the system. This control-oriented model must be accurate enough to ensure satisfactory prediction capabilities and capture the fundamental thermal dynamics of the processes influencing the controlled system, whilst at the same time it has to be simple enough to ensure a reasonable computational time of the optimisation process [20]. In order to ensure the feasibility of the MPC optimisation problem within a prescribed computational time (e.g. lower than the control time-step), the control-oriented model should be formulated to be as close as possible to a Linear Time Invariant (LTI) model [21]. Indeed, the optimisation of non-linear systems requires the adoption of optimization algorithms that do not ensure the reachability of the optimal solution (e.g Genetic Algorithm or Particle Swarm Optimisation) and usually requires a long computational time. A subclass of nonlinear systems, that include both continuous and discrete variables (e.g. Boolean variables 
describing operating modes), are known as hybrid systems which can be formulated as Mixed Logical Dynamical (MLD) or Piecewise Affine (PWA) system [22].

The formulation of the system studied in this paper as a hybrid system helped with many challenges that appear when a formulation of an MPC for such a system is attempted. This solar thermal system is intrinsically non-linear in nature $[13,14]$, particularly if a PCS is adopted as a HTF. Firstly, the specific enthalpy stored by the PCS at different temperatures follows a non-linear trend. This problem was resolved by means of the abovementioned piecewise linearisation of the enthalpy vs. temperature curves. This allowed the system to be considered as a PWA linear system, separating the PCS properties in three linear regions depending on its aggregation state (solid, liquid or in phase change transition). Secondly, the heat exchanges of the solar thermal collector are strongly influenced by non-linear thermal phenomena. Furthermore, the collector performance is influenced by the thermal energy store temperature and vice versa. This non-linearity problem was overcome by excluding the solar collector model from the control-oriented model. In this way, the heat flux delivered by the collector was calculated off-line at every time step and used as input to the control-oriented model (treating it as a measured external disturbance). This was made possible under the assumption that the collector inlet temperature remains constant over the prediction horizon. In a PCS-filled solar collector system this temperature can be reasonably set in the phase change temperature range of the material.

Following the assumptions above, the control-oriented model used to represent the thermal energy store dynamics could be formulated. This model was based on the schematic shown in Figure 4. The measured disturbances affecting the thermal energy store were the ambient air temperature, the space heating demand and the heat delivered by the collector. The controller can regulate the heat delivery of the auxiliary heater and switch between the fixed speed of the solar collector pump and thus regulate the flow-rate in the collector. The heat delivered by the collector is influenced itself by the flow-rate in the collector and by climatic disturbances (i.e. to ambient air temperature, wind speed, solar irradiance, sky temperature).

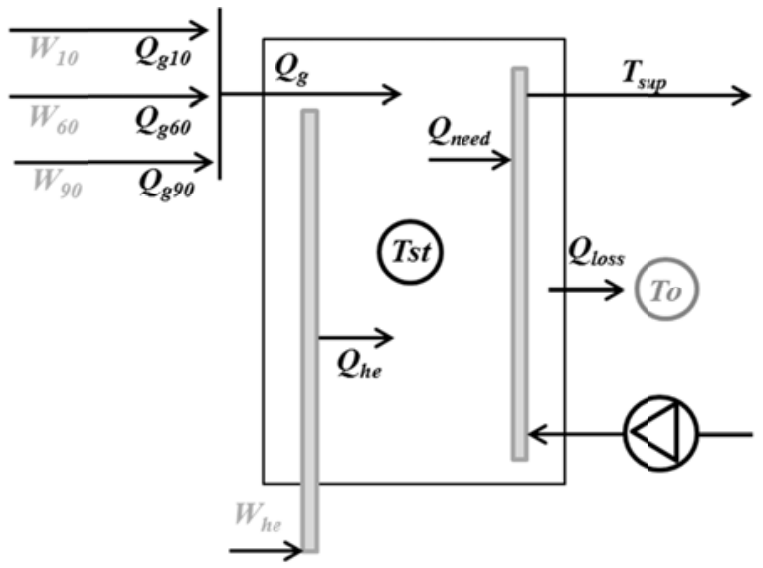

Figure 4. The control-oriented model of the thermal energy store. Thermal fluxes are marked in black, while electrical energy consumptions are in grey.

The MPC problem was formulated using a control time step of $1 \mathrm{~h}$ and a control/prediction horizon of $24 \mathrm{~h}$. The forecasted values of the disturbances are considered deterministic and known a-priori. Indeed, the predicted climatic disturbances affecting the collector and the thermal energy store were derived from the Example Weather Year (EWY) of Turin. The 
prediction of the disturbances was considered to be perfect and equal to the set of values used for the simulation. The prediction of the space heating demand was calculated in advance by re-scaling the daily thermal load profile found in [23]. This profile is representative of a benchmark profile for residential buildings in the studied region. The dwellings considered in [23] are located in Turin (2617 HDD and heating design temperature equal to $-8{ }^{\circ} \mathrm{C}$ ) with an annual space heating energy demand around $90 \mathrm{kWh} / \mathrm{m}^{2}$. The solar thermal system was designed to fulfil at least $50 \%$ of this annual space heating energy demand, while the remaining part of this demand is to be fulfilled by the auxiliary heater [24]. Considering the energy generation during the heating season of the PCS-based collector assessed in [25], a single panel is able to cover around $10 \mathrm{~m}^{2}$ of heated surface of the considered residential building. For this reason the calculations in this paper were referred to an area of $10 \mathrm{~m}^{2}$ of heated surface. The control-oriented model that represents the evolution of the controlled thermal energy store was explicated by means of the following Equation 1:

$$
T_{s t}(k+1)=T_{s t}(k)+\frac{\delta_{10} \cdot \mathcal{Q}_{g 10}(k)+\delta_{60} \cdot \mathcal{Q}_{g 60}(k)+\delta_{90} \cdot \mathcal{Q}_{g 90}(k)+\mathcal{Q}_{h e}(k)-\mathcal{Q}_{n e e d}(k)-U \cdot A \cdot\left(T_{s t}(k)-T_{o}(k)\right)}{\rho_{P C S} \cdot V_{s t} \cdot c_{p, P C S, j}(k)} \cdot \Delta t
$$

where: $\Delta t$ is the sampling time; $k$ is the discrete control time step of the system; $U_{s t}=0.47$ $\mathrm{W} / \mathrm{m}^{2} \mathrm{~K}, A_{s t}=1.75 \mathrm{~m}^{2}, V_{s t}=0.2 \mathrm{~m}^{3}$ are respectively the average thermal transmittance, the total external surface and the volume of the thermal energy store tank; $\rho_{P C S}=950 \mathrm{~kg} / \mathrm{m}^{3}$ is the PCS density; $c_{p, P C S, j}$ is the specific heat of the PCS depending on the state of aggregation of the material at the time $k$ (see Table 1); $T_{s t}$ is the thermal energy store average temperature, thus the system state evolving during time; $Q_{g 10}, Q_{g 60}$ and $Q_{g 90}$ are the available heat generations produced by the solar thermal collector at the various pump speeds calculated by means the external model of the solar thermal collector; $\delta_{10}, \delta_{60}$ and $\delta_{90}$ are the Boolean variables that represent the activation, or not, of the pump at a defined speed; $Q_{h e}$ is the heating delivered by the auxiliary heater; and $Q_{\text {need }}$ is the heating power delivered to address the space heating demand.

In order to properly formulate an Economic MPC controller, with an objective function consisting in the minimisation of the whole system energy demand, the electrical energy consumption of the auxiliary heater and the pump needed to be evaluated and compared during the optimisation process. In this paper, ${ }_{2}$ an electrical heater was adopted as the auxiliary heater, therefore its electrical consumption was equal to the thermal energy supplied $W_{h e}=$ $Q_{h e} \cdot \Delta t$. The pump rates of consumption at the various speeds were determined by experimental tests, resulting in values equal to $W_{10}=0.005 \mathrm{kWh}, W_{60}=0.025 \mathrm{kWh}$, and $W_{90}$ $=0.055 \mathrm{kWh}$, respectively (see Table 2 ). In conclusion, the optimised system had to respect the following hard constraints:

$$
\begin{aligned}
& 0 \leq \mathcal{Q}_{h e} \leq \mathcal{Q}_{h e, \max } \\
& T_{s t} \leq T_{s t, \max }
\end{aligned}
$$

where the first constraint limits the heating power that the auxiliary electric heater can deliver ( $Q_{h e, \max }$ equal to $1.5 \mathrm{~kW}$ ) and the second constraint imposes the maximum temperature allowed in the thermal energy store $\left(T_{s t, \max }=65{ }^{\circ} \mathrm{C}\right)$ due to the material performance limits. Furthermore, the additional soft constraint in Equation (4) was introduced to ensure that the temperature of thermal energy store remains high enough to be able to deliver the required 
heating demand building at each point in time, considering the physical design of the secondary loop that extracts heat from the tank to supply the house:

$$
T_{s t, \min }+e \leq T_{s t}
$$

where $T_{s t, \min }$ is the minimum temperature of the thermal energy store. $T_{s t, \min }$ was determined as a function of $Q_{\text {need }}$ assuming that the system works with a fixed flow-rate and with a constant return water temperature equal to $25{ }^{\circ} \mathrm{C}$. For this reason the profile of $T_{\text {st, min }}$ is related to the heating energy demand profile. The slacking variable $e$ was used to ensure the feasibility of the problem and the stability of the controller. Since in general the demand should be met in its majority, a large weight coefficient $W_{e}$ on this slacking variable was assigned in the objective function. In this case, it was assumed equal to $10 \mathrm{kWh}$ of electrical energy for every kelvin of violation.

The objective function to be minimised was the summation of all electrical energy consuming components:

$$
J=\min \left(h_{\text {need }}^{\&}(k)+\delta_{10}(k) \cdot h_{10}^{\&}+\delta_{60}(k) \cdot W_{60}^{\&}+\delta_{90}(k) \cdot W_{90}^{\&}+e(k) \cdot W_{e}\right)
$$

\section{RESULTS AND DISCUSSION}

The MPC algorithm was formulated by means of the MPT3 Matlab toolbox [26] and the control-oriented model was defined in HYSDEL [27]. The optimisation was achieved using the MPT toolbox and CPLEX as solver for the MILP problem. The average solving time for each control time step was around $10 \mathrm{~s}$ on the PC used for this study (Intel core I7 with $32 \mathrm{~GB}$ of RAM).

The results herewith outlined refer to one week of closed loop simulation. In particular, the $7^{\text {th }}$ week of the EWY was selected for the analysis, as it was considered representative of the winter conditions (average ambient air temperature equal to $4.2{ }^{\circ} \mathrm{C}$ and average direct beam radiation during daylight hours equal to $320 \mathrm{~W} / \mathrm{m}^{2}$ ) and showed an alternation between sunny and cloudy days. Figure 5 shows the disturbances affecting the solar thermal system. In Figure 5 (a) the main weather disturbances including ambient air temperature, direct beam solar radiation, and horizontal diffuse solar radiation are shown. Figure 5 (b) highlights how the heat fluxes produced by the solar thermal collector would vary if the pump operated at the different speeds. The heat fluxes produced by the collector were calculated by means of the numerical model of the collector for each pump speed and at each control time step, for the 24 hours ahead, using the forecasted weather disturbances. In conclusion, in Figure 5 (c) the profile during time of the instantaneous space heating demand is reported.

In Figure 6 (a) is shown the optimal control sequence evaluated through the closed loop simulation of the MPC algorithm. The flow-rate corresponding to the different fixed pump speeds are marked on the primary y-axis, while the power required to the electric heater is marked on the secondary y-axis. Being the control time-step equal to $1 \mathrm{~h}$, the control inputs were a stepwise function. The result of the solicitation of the uncontrolled disturbances and control inputs was the evolution during time of the controlled system state, which was the thermal energy store temperature. The evolution of the controlled state is shown in Figure 6 (b). In this chart, the actual thermal energy store temperature is compared with the minimum thermal energy store temperature required to ensure the complete fulfilling of space heating 
demand. The temperatures that delimit the phase change transition are displayed with dashed lines on the chart. The thermal energy store initial temperature was set equal to $35{ }^{\circ} \mathrm{C}$ to represent the thermal energy already stored in the previous days.

The resulting weekly energy demand - equal to the summation of the space heating demand and the thermal energy store losses - was $29.1 \mathrm{kWh}$. The collector delivered $61.4 \%$ of this amount, while the electric heater and the thermal energy store respectively delivered $36.2 \%$ and $2.4 \%$. Furthermore, a share of $2.3 \%$ of the space heating demand was not satisfied. This happened when thermal energy store temperature was lower than the minimum temperature required by the space heating system. These were the cases when the controller violated the slacking variable instead of using the electric heater. In particular, this violation of the soft constraint occurred during the first days of the simulation during peak hours. This phenomenon is was strongly affected by the initial condition settings.
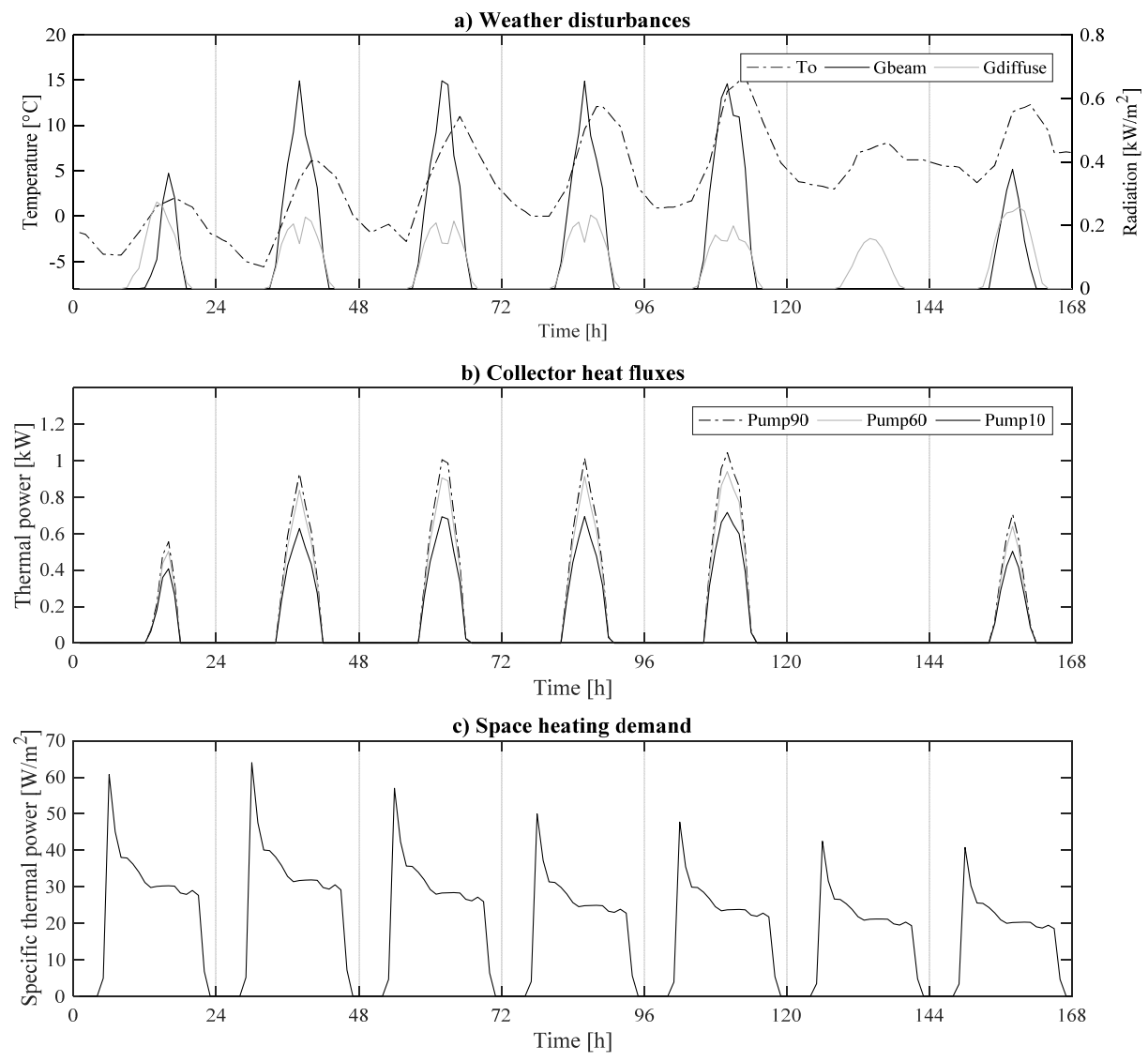

Figure 5. Disturbances affecting the controlled system. (a) The weather disturbances. (b) The forecasted profiles of heat power generation by the solar thermal collector at different fixed pump speeds. (c) The required space heating demand profile.

Figure 6 (a) highlights how the MPC algorithm regulates the solar thermal system. The electric consumption of the pump was considerably lower than that of the electric heater, thus the MPC controller attempted to exploit the renewable energy source as much as possible. In the first days and in the $6^{\text {th }}$ day, the renewable energy source was not available or sufficient to fulfil the energy demand, therefore the electric heater was switched on. The lower the pump speed, the lower the electrical energy consumption (Table 2), but also the higher the amount of energy not delivered by the collector (Figure 5 (b)). The pump speed regulation by MPC 
ensured the trade-off between this two contrasting functions, exploiting high speeds only when necessary. From Figure 6 (b) can be inferred how the MPC algorithm tends to maintain the TES temperature within the PCS phase change range. Furthermore, Figure 6 (b) highlights how the receding horizon formulation allowed the space heating demand requirement to be anticipated by the system, which supercharged the thermal energy store when the renewable energy source was available.
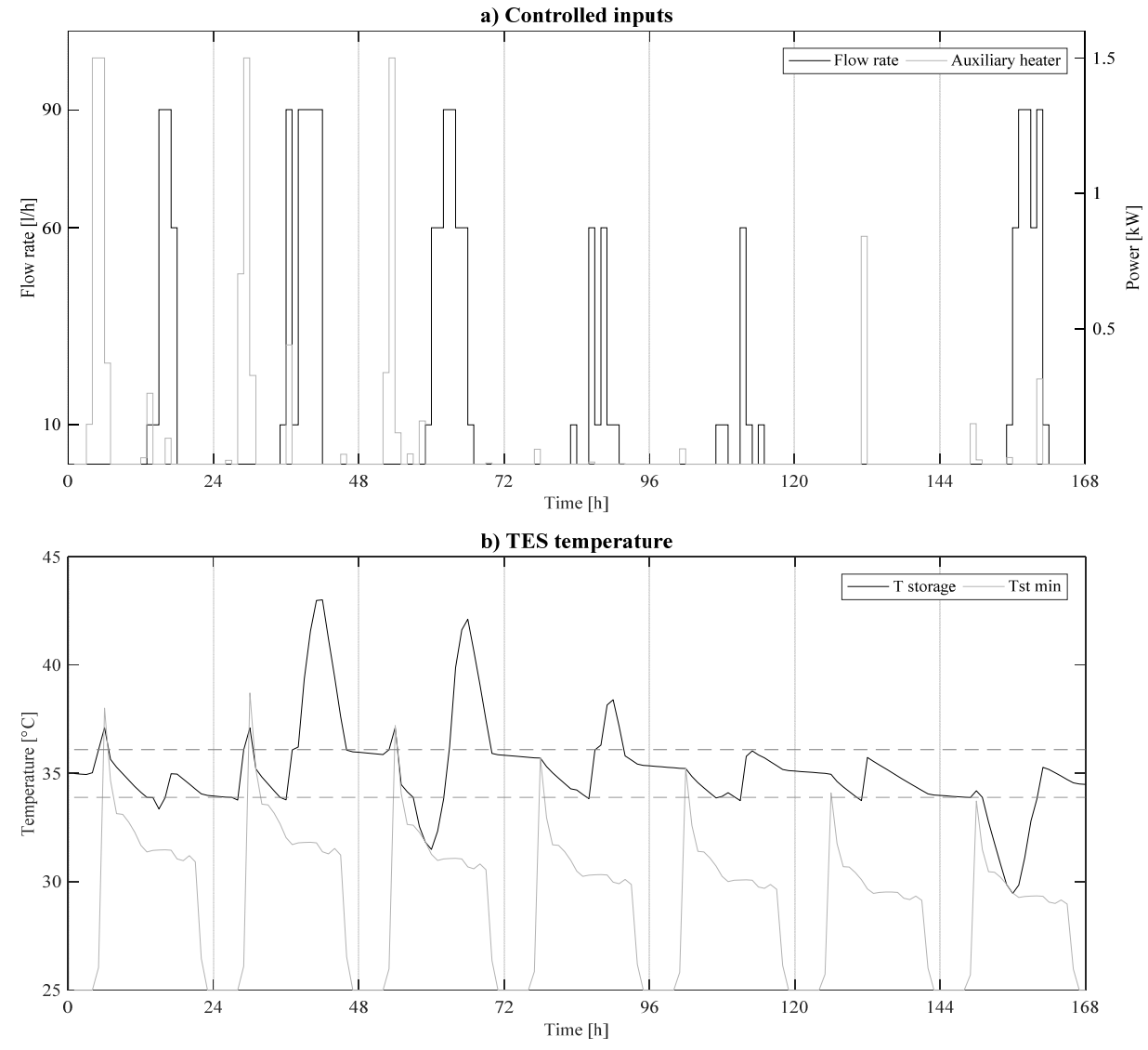

Figure 6. (a) The system controlled inputs, such as the pump flow-rate and the electric heater power. (b) The thermal energy store temperature evolution, resulting from the application of the optimal control input sequence, compared with the minimum thermal energy store temperature required.

\section{CONCLUSION}

The present paper describes the formulation of an MPC algorithm for regulating a solar thermal system for residential space heating. In particular, the system involved the use of a PCS and it required an innovative optimal control to properly exploit its benefits. The developed model proved to be robust and reliable, and laid the basis for further investigations aimed at assessing the economic impact in comparison to more traditional control strategies. The problem was formulated by means of numerical models calibrated with real data gathered from a full-scale prototype. Closed-loop simulations were performed for one representative week of the heating season for the climatic conditions of Turin. A solution for dealing with the non-linearity that intrinsically affects this formulation was herewith proposed. Results showed how the MPC algorithm was capable of selecting the control sequence that optimises an objective function with 
economic goals. This represents a great potential benefit both in terms of energy consumption reduction and in terms of reducing the temporal mismatch between the solar energy availability and the building energy demand. Future work will compare the MPC controller with other baseline controllers, implement stochasticity of the disturbances and simulate the effect of the violation of the minimum thermal energy store temperature on the indoor occupant comfort.

\section{NOMENCLATURE}

$\begin{array}{ll}A_{s t} & {\left[\mathrm{~m}^{2}\right]} \\ c_{p, P C S, j} & {[\mathrm{~kJ} / \mathrm{kgK}]} \\ d h_{P C S, t r} & {[\mathrm{~kJ} / \mathrm{kg}]} \\ \Delta t & {[\mathrm{~s}]} \\ k & {[\mathrm{~h}]} \\ \delta_{10}, \delta_{60}, \delta_{90} & {[0-1]} \\ Q_{h e, \max } & {[\mathrm{kW}]} \\ Q_{g 10}, Q_{g 60}, Q_{g 90} & {[\mathrm{~kW}]} \\ Q_{h e} & {[\mathrm{~kW}]} \\ Q_{\text {need }} & {[\mathrm{kW}]} \\ T_{\text {sup }, P C S}, T_{\text {inf }, P C S} & {\left[{ }^{\circ} \mathrm{C}\right]} \\ T_{s t} & {\left[{ }^{\circ} \mathrm{C}\right]} \\ T_{o} & {\left[{ }^{\circ} \mathrm{C}\right]} \\ T_{s t, \text { max }}, T_{\text {st,min }} & {\left[{ }^{\mathrm{C}}\right]} \\ U_{s t} & {\left[\mathrm{~W} / \mathrm{m}^{2} \mathrm{~K}\right]} \\ V_{s t} & {\left[\mathrm{~m}{ }^{3}\right]} \\ W_{h e}, W_{10}, W_{60}, W_{90} & {[\mathrm{kWh}]} \\ W_{e} & {[\mathrm{kWh} / \mathrm{K}]} \\ \rho_{P C S} & {\left[\mathrm{~kg} / \mathrm{m}^{3}\right]}\end{array}$

external surface of the thermal energy store tank specific heat of the PCS total phase change specific enthalpy of the PCS sampling time discrete control time step of the system fixed pump speeds maximum power deliverable by the auxiliary heater heat flux delivered by the solar thermal collector heating power delivered by the auxiliary heater heating power required for space heating higher and lower phase change temperature of the PCS thermal energy store temperature ambient air temperature maximum and minimum storage temperature limits thermal transmittance of the thermal energy store volume of the thermal energy store electric consumption weight coefficients soft constraint violation weight coefficient PCS density

\section{REFERENCES}

1. Pérez-Lombard, L.; Ortiz, J. and Pout, C., A review on buildings energy consumption information, Energy Build., Vol. 40, No. 3, pp 394-398, 2008.

2. Rodriguez-Ubinas, E.; Ruiz-Valero, L.; Vega, S. and Neila, J., Applications of Phase Change Material in highly energy-efficient houses, Energy Build., Vol. 50, pp 49-62, 2012.

3. Mehling, H. and Cabeza, L.F., Heat and cold storage with PCM. Springer, Berlin, 2008

4. Rabin, Y.; Bar-Niv, I.; Korin, E. and Mikic, B., Integrated solar collector storage system based on a salt-hydrate phase-change material, Sol. Energy, Vol. 55, No. 6, pp 435-444, 1995.

5. Eames, P.C. and Griffiths, P.W., Thermal behaviour of integrated solar collector/storage unit with $65{ }^{\circ} \mathrm{C}$ phase change material, Energy Convers. Manag., Vol.47, No. 20, pp 3611-3618, 2006

6. Fiorentini, M.; Cooper, P. and Ma, Z., Development and optimization of an innovative HVAC system with integrated PVT and PCM thermal storage for a net-zero energy retrofitted house, Energy Build., Vol. 94, pp 21-32, 2015.

7. Ibáñez, M.; Cabeza; L.F.; Solé, C.; Roca, J. and Nogués, M., Modelization of a water tank including a PCM module, Appl. Therm. Eng., Vol. 26, No. 11-12, pp 1328-1333, 2006.

8. Široký, J.; Oldewurtel, F.; Cigler, J. and Prívara, S., Experimental analysis of model predictive control for an energy efficient building heating system, Appl. Energy, Vol. 88, No. 9, pp 3079-3087, 2011. 
9. Prívara, S.; Široký, J.; Ferkl, L. and Cigler, J., Model predictive control of a building heating system: The first experience, Energy Build., Vol. 43, No. 2-3, pp 564-572, 2011.

10. Fiorentini, M.; Cooper, P.; Ma, Z. and Robinson, D.A., Hybrid model predictive control of a residential HVAC system with PVT energy generation and PCM thermal storage, Energy Procedia, Vol. 83, pp 21-30, 2015.

11. Fiorentini, M.; Wall, J.; Ma, Z.; Braslavsky, J.H. and Cooper, P., Hybrid model predictive control of a residential HVAC system with on-site thermal energy generation and storage, Appl. Energy, Vol. 187, pp 465-479, 2017.

12. Halvgaard, R.; Poulsen, N.K.; Madsen, H. and Jorgensen, J.B., Economic Model Predictive Control for building climate control in a Smart Grid, 2012 IEEE PES Innov. Smart Grid Technol., pp 1-6, 2012.

13. Zambrano, D.; Bordons, C.; García-Gabín, W. and Camacho, E.F., A Solar Cooling Plant: a Benchmark for Hybrid Systems Control, IFAC Proc., Vol. 39, No. 5, pp 199204, 2006.

14. Menchinelli, P and Bemporad, A., Hybrid Model Predictive Control of a Solar Air Conditioning Plant, Eur. J. Control, Vol. 14, No. 6, pp 1-15, 2008.

15. Serale, G.; Fabrizio, E. and Perino, M., Design of a low-temperature solar heating system based on a slurry Phase Change Material (PCS), Energy Build., Vol. 106, pp 44-58, 2015.

16. Serale, G.; Cascone, Y.; Capozzoli, A.; Fabrizio, E. and Perino, M., Potentialities of a low temperature solar heating system based on slurry phase change materials (PCS), Energy Procedia, Vol. 62, pp 355-363, 2014.

17. Serale, G.; Goia, F. and Perino, M., Numerical model and simulation of a solar thermal collector with slurry Phase Change Material (PCM) as the heat transfer fluid, Sol. Energy, Vol. 134, pp 429-444, 2016.

18. Buttitta, G.; Serale, G. and Cascone, Y., Enthalpy-temperature evaluation of slurry phase change materials with T-history method, Energy Procedia, Vol. 78, pp 1877-1882, 2015.

19. Genovese, A.; Amarasinghe, G.; Glewis, M.; Mainwaring, D. and Shanks, R.A., Crystallisation, melting, recrystallisation and polymorphism of n-eicosane for application as a phase change material, Thermochim. Acta., Vol. 443, No. 2, pp 235-244, 2006.

20. Prívara, S.; Cigler, J.; Váňa, Z.; Oldewurtel; F., Sagerschnig, C. and Žáčeková, E., Building modeling as a crucial part for building predictive control, Energy Build., Vol. 56, pp 8-22, 2013.

21. Camacho, E.F. and Bordons, C., Model predictive control. Springer Science \& Business Media, London, 2013.

22. Borrelli, F.; Bemporad, A. and Morari, M. Predictive control for linear and hybrid systems. Cambridge University Press, Cambridge, 2011.

23. Kazas, G.; Fabrizio, E. and Perino, M., Energy demand profile generation with detailed time resolution at an urban district scale: A reference building approach and case study, Appl. Energy, Vol. 193, pp 243-262, 2017.

24. Duffie, J.A. and Beckman, W.A., Solar engineering of thermal processes, $4^{\text {th }}$ edition. John Wiley \& Sons, Hoboken, 2013.

25. Serale, G.; Baronetto, S.; Goia, F. and Perino, M., Characterization and energy performance of a slurry PCM-based solar thermal collector: a numerical analysis. Energy Procedia, Vol. 48, pp 223-232, 2014.

26. Herceg, M.; Kvasnica, M.; Jones, C.N. and Morari, M., Multi-parametric toolbox 3.0, Control Conf. (ECC) 2013 Eur., pp 502-510, 2013.

27. Torrisi, F.D. and Bemporad, A., HYSDEL-A Tool for Generating Computational Hybrid Models for Analysis and Synthesis Problems, IEEE Trans. Control Syst. Technol., Vol. 12, No. 2, pp 1-27, 2004. 